\title{
Wake-up stroke in a young woman with rotational vertebral artery occlusion due to far-lateral cervical disc herniation
}

\author{
Masakazu Okawa, MD, PhD, ${ }^{1}$ Takaaki Amamoto, MD, ${ }^{1}$ Hiroshi Abe, MD, PhD, ${ }^{1}$ \\ Sohei Yoshimura, MD, PhD, ${ }^{2}$ Toshio Higashi, MD, PhD, ${ }^{1}$ and Tooru Inoue, MD, PhD' \\ 'Department of Neurosurgery, Faculty of Medicine, Fukuoka University; and 2Department of Neurology, Fukuoka Red Cross \\ Hospital, Fukuoka, Japan
}

\begin{abstract}
Wake-up stroke is most likely to be caused by small-vessel disease, and is related to snoring. The authors present a rare case of far-lateral cervical disc herniation with neck rotation, resulting in wake-up stroke in a young woman. The patient, a 31-year-old woman, was admitted to the hospital because of dysarthria and confusion when she awoke in the morning. Brain MRI showed acute infarction in the posterior fossa. Cerebral angiography showed thrombus in the distal top of the basilar artery and the bilateral posterior cerebral arteries. During angiography, the thrombus size decreased with heparinization. There was severe stenosis of the right vertebral artery (VA) at C5-6, and head rotation to the right resulted in complete occlusion of the right VA. Neck MRI showed far-lateral intervertebral disc herniation. Surgical decompression of the VA was performed via the anterior cervical approach. Histological examination showed a degenerative intervertebral disc. Postoperative angiography confirmed successful decompression of the VA.
\end{abstract}

http://thejns.org/doi/abs/10.3171/2014.11.SPINE14393

KEY WORDS wake-up stroke; rotational vertebral artery occlusion; basilar occlusion; cervical disc herniation

$\mathrm{R}$ YAN and Cope first reported cervical vertigo, characterized by vertigo, dizziness, and blurred vision with head rotation, in $1955 .{ }^{8}$ In 1957 , Tissington Tatlow and Bammer described vertebrobasilar insufficiency (VBI) resulting from compression of the vertebral artery (VA) during head rotation. ${ }^{14}$ Since then, many patients with symptoms related to compression of the VA have been reported. ${ }^{4}$

Stenosis of the VA typically occurs at the atlantoaxial level, resulting in "bow hunter stroke" when the head is turned to the opposite side. ${ }^{12}$ Stenosis of the $V_{1}$ portion of the VA causes symptoms referred to as the Powers syndrome. ${ }^{6}$ The $\mathrm{V}_{2}$ portion of the VA is susceptible to compression by osteophytes and other degenerative changes associated with cervical spondylosis. Compression of the VA causes VBI, and may rarely cause embolic stroke in young patients. ${ }^{4,9,15}$ We report a very rare case of VA compression by lateral cervical disc herniation with neck rotation, resulting in wake-up stroke.

\section{Case Report}

History and Examination

A 31-year-old woman with Type 1 diabetes mellitus was admitted to the hospital because of dysarthria and confusion when she awoke in the morning. Brain MRI studies obtained on admission showed fresh infarction in the cerebellum and midbrain. Admission MR angiography showed a defect in the distal basilar artery (BA) (Fig. 1). There was thrombus in the distal BA and the bilateral $\mathrm{P}_{1}$ portions of the posterior cerebral arteries (PCAs) (Fig. 2A). During angiography, the thrombus size decreased with heparinization (Fig. 2B). There was severe stenosis of the right VA at C5-6 (Fig. 3A), and head rotation to the right caused complete occlusion of the right VA (Fig. 3B). Electrocardiography did not show atrial fibrillation. Aspirin and clopidogrel were prescribed, and the patient's neurological symptoms improved over several weeks. Neck MRI showed far-lateral cervical disc herniation (Fig. 4A),

ABBREVIATIONS BA = basilar artery; $\mathrm{PCA}=$ posterior cerebral artery; $\mathrm{VA}=$ vertebral artery; $\mathrm{VBI}=$ vertebrobasilar insufficiency. SUBMITTED April 23, 2014. ACCEPTED November 6, 2014.

INCLUDE WHEN CITING Published online May 1, 2015; DOI: 10.3171/2014.11.SPINE14393.

DISCLOSURE The authors report no conflict of interest concerning the materials or methods used in this study or the findings specified in this paper. 

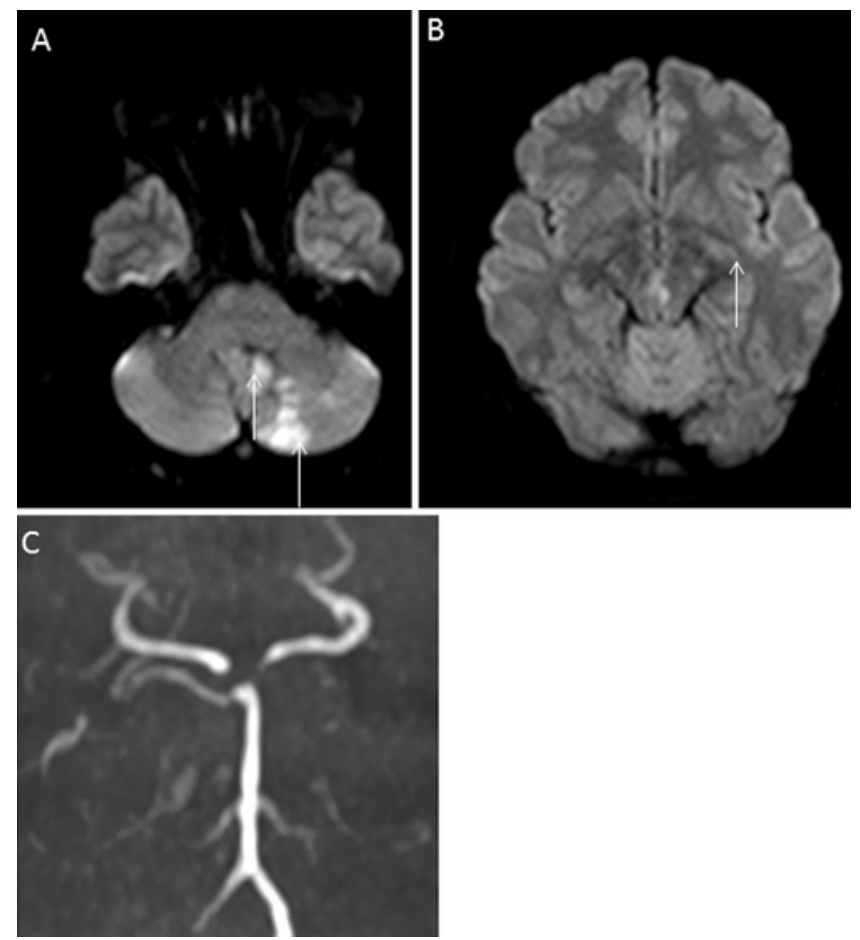

FIG. 1. Brain MRI (A and B) and MR angiography (C) studies showing fresh infarction in the cerebellum and midbrain (arrows).

and 3D CT angiography showed persistent severe stenosis of the right VA (Fig. 4B). The patient complained of dizziness with head rotation, and was placed in a hard cervical collar until surgery.

\section{Operation}

After a month from onset, surgery was performed under general anesthesia by using a right anterior approach to the cervical spine. The longus colli muscle was dissected and mobilized laterally. The osseous canal of the right VA was unroofed anteriorly and laterally at the C-5 and C-6 levels using a high-speed drill. Intraoperative Doppler ultrasonography and indocyanine green videoangiography confirmed pulsation and decompression of the VA. Anterior fusion was not performed because there was no instability of the cervical spine. Histological examination

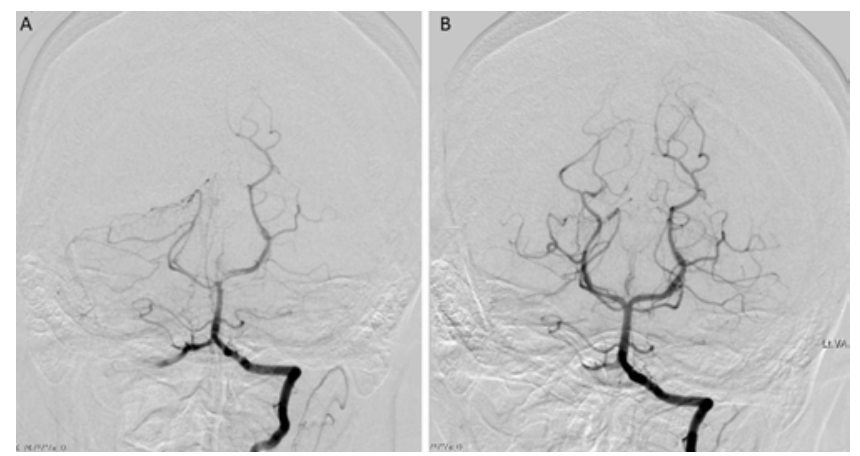

FIG. 2. A: Right vertebral angiography study showing thrombus in the distal $B A$ and the bilateral $P_{1}$ portions of the PCAs. B: During angiography, the thrombus size decreased without thrombolysis or mechanical thrombectomy.
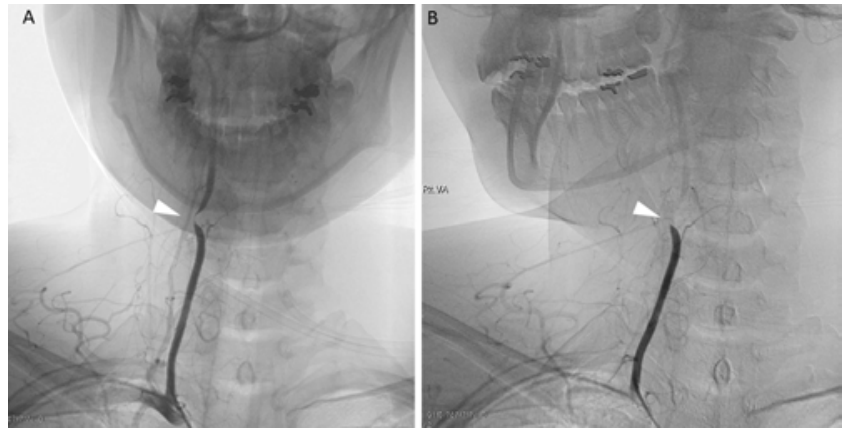

FIG. 3. Angiography studies. A: There was severe stenosis of the right VA at C5-6 without head rotation (arrowhead). B: Head rotation to the right resulted in complete occlusion of the right VA (arrowhead).

showed a degenerative intervertebral disc, with degenerative nucleus pulposus tissue and fibrocartilage with areas of mixed change, and some necrotic cells and fibers.

\section{Postoperative Course}

The patient returned to her daily activities without limitations 1 month after surgery. Postoperative angiography confirmed decompression of the right VA (Fig. 5).

\section{Discussion}

Far-lateral disc herniation usually occurs in the lumbar spine, with a reported incidence of $5.8 \%-11.7 \% .^{1}$ In the lumbar spine, classic posterolateral disc herniation compresses the nerve root exiting the spinal canal at the level below, whereas far-lateral cervical disc herniation compresses the nerve root at the same or upper level. In the cervical spine, the VA passes through the transverse foramina lateral to the nerve roots at $\mathrm{C} 2-6$. Far-lateral cervical disc herniation can therefore compress the VA.

Cervical disc herniation seldom causes rotational VA occlusion. Compression of the VA at the C2-6 level during head rotation is usually caused by osteophytes and degenerative changes associated with cervical spondylosis. ${ }^{4}$ To the best of our knowledge, only 4 previous cases of rotational VA occlusion associated with cervical disc herniation have been reported (Table 1); ;,5,16,17 these cases
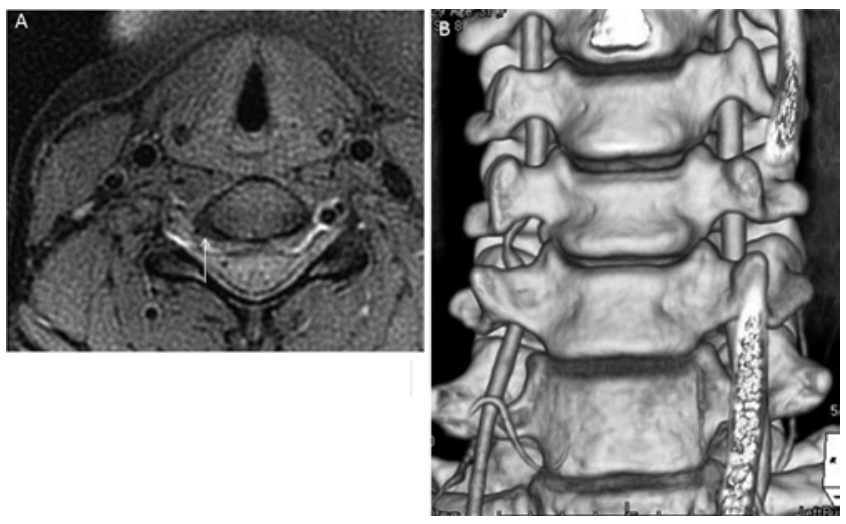

FIG. 4. A: Neck MRI study. This T1-weighted image with fat suppression shows far-lateral disc herniation at C5-6 (arrow) and narrowing of the right transverse foramen. B: Preoperative 3D CT angiography study showing severe stenosis of the right VA. 
TABLE 1. Previously reported cases of VA rotational occlusion associated with a herniated cervical intervertebral disc

\begin{tabular}{|c|c|c|c|c|c|c|c|c|}
\hline Authors \& Year & $\begin{array}{l}\text { Pt Age } \\
\text { (yrs), } \\
\text { Sex }\end{array}$ & Level & Clinical Manifestation & $\begin{array}{c}\text { Mechanism of } \\
\text { Stroke }\end{array}$ & $\begin{array}{l}\text { Compressing } \\
\text { Factors }\end{array}$ & $\begin{array}{c}\text { Angio Findings w/o } \\
\text { Head Rotation }\end{array}$ & $\begin{array}{c}\text { VA Angio } \\
\text { Findings w/ } \\
\text { Head Rotation }\end{array}$ & $\begin{array}{l}\text { Surgical } \\
\text { Approach }\end{array}$ \\
\hline Budway \& Senter, 1993 & $45, M$ & C5-6 & Visual loss & Embolic & Disc & Near occl thrombus & Occl & Anterior \\
\hline Vates et al., 2002 & $56, M$ & C4-5 & Dizziness, syncope & Positional VBI & Disc fragment & Normal & Occl & Anterior \\
\hline Nemecek et al., 2003 & $49, M$ & $\mathrm{C}-7$ & Vertigo, syncope & Positional VBI & Disc fragment & Normal & Occl & Anterior \\
\hline Ujifuku et al., 2009 & $78, \mathrm{M}$ & C4-5 & Blurred vision, syncope & Positional VBI & Ossified disc & Normal & Occl & Anterior \\
\hline Present study & $31, F$ & C5-6 & Confusion, dysarthria & Embolic WUS & Disc & Severe stenosis & Occl & Anterior \\
\hline
\end{tabular}

Angio = angiographic; occl = occlusion; pt = patient; WUS = wake-up stroke.

were all in middle-aged or elderly men. In 3 of these 4 cases, the VA was occluded by head rotation, but had a normal appearance when the head was in the neutral position; positional VBI occurred without stroke.,16,17 In the case reported by Budway and Senter and in our case, there was severe stenosis of the VA even without head rotation, ${ }^{3}$ and MRI showed far-lateral protrusion of the disc into the transverse foramen.

Tanimoto et al. reported that wake-up stroke was most likely to be caused by small-vessel disease..$^{13}$ In our case, we assume that the blood flow was slowed in the distal portion of the VA because of head rotation during sleep. Prolonged occlusion time because the head position was not changed frequently during sleep resulted in clot formation in the VA. When the head position was changed and blood flow resumed, the clot caused an embolic stroke. In individuals without VA stenosis, this is unlikely to occur because the VA would not be occluded by mild rotation of the head.

For patients presenting with wake-up stroke, the time they were last seen healthy is defined as the time they fell asleep, which places them outside the window for thrombolysis performed using tissue plasminogen activator. Fortunately, the clot in the BA decreased in size with heparinization during routine angiography in our case.

To prevent recurrence of stroke, decompression of the VA was essential in our patient. The factors causing compression were evaluated using MRI and CT angiography. Dynamic angiography is the gold standard for diagnosis of dynamic factors. Transcranial Doppler ultrasonography

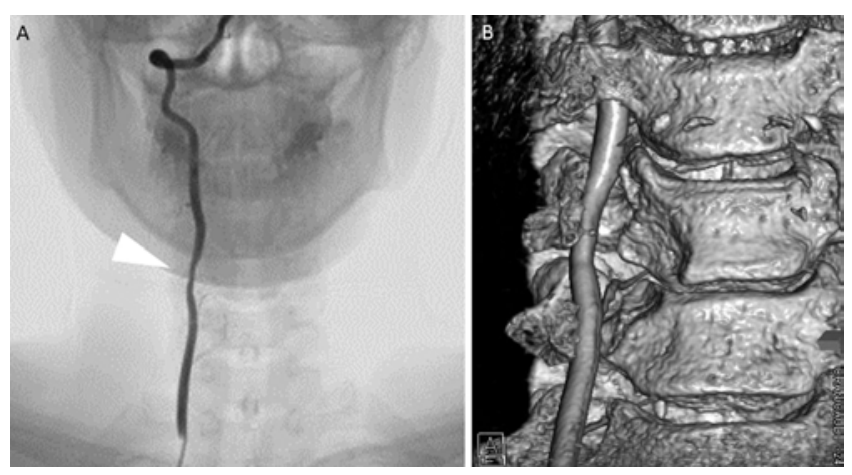

FIG. 5. A: Postoperative angiography study showing that the VA stenosis had improved (arrowhead). B: Postoperative 3D CT angiography study showing improvement of the stenosis. may be feasible in cases with positional VBI. ${ }^{17}$ Neck immobilization with a collar is necessary during the preoperative period.

The anterior cervical approach is frequently used for decompression of the VA, and was used in all 4 previously reported cases. The anterior approach is useful for direct decompression of the VA and removal of the posterior elements. ${ }^{2}$ The posterior approach may be useful for opening the adjacent intervertebral disc space. ${ }^{7,10}$ Cervical spine fusion has not been shown to improve the postoperative outcome. ${ }^{2,11}$ Fusion would, however, be indicated in cases of VA compression due to subluxation of the cervical vertebrae. $^{4}$

\section{Conclusions}

Cervical disc herniation may cause wake-up stroke in young patients.

\section{References}

1. Abdullah AF, Wolber PG, Warfield JR, Gunadi IK: Surgical management of extreme lateral lumbar disc herniations: review of 138 cases. Neurosurgery 22:648-653, 1988

2. Bakay L, Leslie EV: Surgical treatment of vertebral artery insufficiency caused by cervical spondylosis. J Neurosurg 23:596-602, 1965

3. Budway RJ, Senter HJ: Cervical disc rupture causing vertebrobasilar insufficiency. Neurosurgery 33:745-747, 1993

4. Kuether TA, Nesbit GM, Clark WM, Barnwell SL: Rotational vertebral artery occlusion: a mechanism of vertebrobasilar insufficiency. Neurosurgery 41:427-433, 1997

5. Nemecek AN, Newell DW, Goodkin R: Transient rotational compression of the vertebral artery caused by herniated cervical disc. Case report. J Neurosurg 98 (1 Suppl):80-83, 2003

6. Powers SR Jr, Drislane TM, Nevins S: Intermittent vertebral artery compression; a new syndrome. Surgery 49:257-264, 1961

7. Reulen HJ, Pfaundler S, Ebeling U: The lateral microsurgical approach to the "extracanalicular" lumbar disc herniation. I: A technical note. Acta Neurochir (Wien) 84:64-67, 1987

8. Ryan GM, Cope S: Cervical vertigo. Lancet 269:1355-1358, 1955

9. Saito K, Hirano M, Taoka T, Nakagawa H, Kitauchi T, Tanizawa E, et al: Artery-to-artery embolism with a mobile mural thrombus due to rotational vertebral artery occlusion. J Neuroimaging 20:284-286, 2010

10. Shimizu T, Waga S, Kojima T, Niwa S: Decompression of the vertebral artery for bow-hunter's stroke. Case report. J Neurosurg 69:127-131, 1988

11. Smith DR, Vanderark GD, Kempe LG: Cervical spondylosis 
causing vertebrobasilar insufficiency: a surgical treatment. J Neurol Neurosurg Psychiatry 34:388-392, 1971

12. Sorensen BF: Bow hunter's stroke. Neurosurgery 2:259-261, 1978

13. Tanimoto A, Mehndiratta P, Koo BB: Characteristics of wake-up stroke. J Stroke Cerebrovasc Dis 23:1296-1299, 2013

14. Tissington Tatlow WF, Bammer HG: Syndrome of vertebral artery compression. Neurology 7:331-340, 1957

15. Tominaga T, Takahashi T, Shimizu H, Yoshimoto T: Rotational vertebral artery occlusion from occipital bone anomaly: a rare cause of embolic stroke. Case report. J Neurosurg 97:1456-1459, 2002

16. Ujifuku K, Hayashi K, Tsunoda K, Kitagawa N, Hayashi T, Suyama K, et al: Positional vertebral artery compression and vertebrobasilar insufficiency due to a herniated cervical disc. J Neurosurg Spine 11:326-329, 2009

17. Vates GE, Wang KC, Bonovich D, Dowd CF, Lawton MT:
Bow hunter stroke caused by cervical disc herniation. Case report. J Neurosurg 96 (1 Suppl):90-93, 2002

\section{Author Contributions}

Conception and design: Okawa, Abe, Inoue. Acquisition of data: Okawa, Amamoto. Analysis and interpretation of data: Okawa. Drafting the article: Okawa, Amamoto. Critically revising the article: Okawa. Approved the final version of the manuscript on behalf of all authors: Okawa. Statistical analysis: Okawa. Administrative/technical/material support: Okawa. Study supervision: all authors.

\section{Correspondence}

Masakazu Okawa, Department of Neurosurgery, Fukuoka University, 7-45-1 Nanakuma, Jonan-Ku, Fukuoka 814-0180, Japan. email: okawam@fukuoka-u.ac.jp. 